\title{
CONTRACEPTIVE KNOWLEDGE AND PERCEPTION AMONG SCHOOL GOING ADOLESCENT GIRLS IN INDORE CITY
}

\author{
Vaishali Jain ${ }^{1}$, Sonal Jain ${ }^{2}$, Chandra Prabha Jain ${ }^{3}$
}

${ }^{1}$ Consultant, Department of Obstetrics and Gynaecology, Mahaveer Hospital, Indore. ${ }^{2}$ Consultant, Department of Obstetrics and Gynaecology, Mahaveer Hospital, Indore. ${ }^{3}$ Consultant, Department of Obstetrics and Gynaecology, Mahaveer Hospital, Indore.

\section{ABSTRACT}

The present study was undertaken to assess the knowledge and perception regarding contraceptives among the 1000 adolescent school going girls in Indore City.

\section{MATERIAL AND METHOD}

Based on a predesigned, pretested, and structured questionnaire contraception score was calculated for every girl. Effect of factors such as age, mother's education, type of family, and type of school on contraceptive score was calculated.

\section{RESULTS}

Majority of girls belonged to mid adolescent group i.e. $86.6 \% .66 \%$ belonged to English-medium private school and only $34 \%$ from Hindi-medium government school. Majority of girls lived in nuclear family (58.7\%). 53.7\% girls had average contraceptive score, $35.1 \%$ had good score. Only $11.2 \%$ had poor score. Late adolescent had a good score as compared to early and mid-adolescent. Girls whose mothers were graduate and postgraduate scored better. Girls in English-medium private school scored better .Most important source of information was television (29.2\%) followed by mother (15.3\%).

\section{KEYWORDS}

Contraceptive, Knowledge, Perception, Adolescent Girls.

HOW TO CITE THIS ARTICLE: Jain V, Jain S, Jain CP. Contraceptive knowledge and perception among school going adolescent girls in indore city. J. Evolution Med. Dent. Sci. 2016;5(67):4805-4808, DOI: 10.14260/jemds/2016/1095

\section{INTRODUCTION}

The term adolescent is derived from Latin word "adolescere" meaning "to grow to mature." WHO has defined adolescents as person between 10-19 years of age.[1] They constitute about $18 \%$ of the world population, i.e. about 1.2 billion.[2] About $88 \%$ of them live in the developing countries. India has the largest (243 million) number of adolescents comprising one fourth of the country's population. ${ }^{[3]}$ Adolescent pregnancies constitute $10-15 \%$ of total pregnancies in India. This is largely attributed to early marriage, a culture widely prevalent in Indian subcontinent.[4] Promoting the healthy practices during adolescence is critical to the future of a country's health.[5] Millennium Development Goals (MDGs) five and six are particularly relevant to young people's health.[6] Providing equitable, comprehensive, Accessible Adolescent Reproductive and Sexual Health Services (ARSH) has been a mandate of Reproductive and Child Health (RCH) program under NRHM in India since 2006.[7] Modernisation, increasing impact of media, decline of parental authority, and increasing gender equality has given rise to a culture that makes sexual activity more appealing and acceptable to adolescent without putting much weight or responsibility on sexual behaviour. They face significant risks and are vulnerable to unplanned pregnancy and STDs, a crucial step in order to avoid above

Financial or Other, Competing Interest: None.

Submission 09-06-2016, Peer Review 15-07-2016,

Acceptance 21-07-2016, Published 22-08-2016.

Corresponding Author:

Dr. Vaishali Jain,

Mahaveer Hospital

A-2, SCH No. 71,

Footi Kothi Square Ring Road,

Indore,

Madhya Pradesh.

E-mail: dr_vaishalijain@yahoo.com

DOI: $10.14260 /$ jemds/2016/1095 problems is to equip young people with proper sexual and reproductive health information (Such as reproductive biology, contraceptive methods, and how STDs are contracted, treated, and prevented and skills such as how to manage sexual relationships). Parents and teachers, however, avoid any mention to this information with children because it is still regarded as taboo subject in Indian society and secondly they themselves lack scientific knowledge about it against this background present study attempts to assess awareness among school going adolescents girls on reproductive health.

\section{AIMS AND OBJECTIVES}

To assess the knowledge of adolescent girls about contraception and to study factors, which influence level of awareness among these girls.

\section{MATERIAL AND METHODS}

A community-based cross-sectional study was carried out between September 2007-2009 in Dept. of Obstetrics and Gynaecology, MGMMC, Indore (M.P.). Two Hindi-medium government schools, i.e. Shaskiya Ahilya Ashram Avam Chandravati Kanya Ucch Mahavidhyalay, no. 1 and Shaskiya Malav Kanya Uchchatar Madhyamik Vidhyalay and one English-medium private School, i.e. St. Raphael's Girls' Higher Secondary School were randomly selected for the study. All were exclusively girls' schools. After designing the study questionnaire, the approval of research and ethics committee of the hospital was sought and obtained. It was given to 1000 female students in three secondary schools in Indore city. The school authorities were approached and consent duly obtained. The proforma was kept confidential without disclosing their identity.

The investigator initially addressed all participants emphasised the objectives of the study and assured them of 
the strict confidentiality of their responses. They were also urged to avoid discussing the question among themselves while completing the questionnaire. It consisted of two sections. First section consisted of questions regarding general information of the students, i.e. age, religion, type of school, class in which students was studying, and mother's educational status. Second section consisted of question regarding contraceptives and STDs including HIV and source of information about above aspects. Each session consisted of 40 students and each session took about 1 hour. In the first forty minutes, students were asked to attempt the questionnaire. After collecting the questionnaire, a lecture was delivered addressing all the questions and then another. 10 min. were devoted to open discussion and doubts of students were cleared. According to responses of students, each student was given a score of poor, average, or good. Hence, contraceptive score and STD score for each students was obtained. Factors which influence these scores were evaluated.

\section{RESULTS}

Table 1 show the demographic profile of the study population. In this study, majority of girls belonged to the mid adolescent age group, i.e. $86.6 \%$. Table 2 shows that $66 \%$ were from private English-medium school. 34\% were from government Hindi-medium school. Table 3 reveals that $53.7 \%$ girls had average contraception score, $11.2 \%$ had poor score, and only $35 \%$ had good score.

\section{FACTORS AFFECTING CONTRACEPTION SCORE}

Age

Table 4 shows in early adolescents most had average score (76\%). In mid adolescents, most had average (52.7\%) or good score (36\%). In late adolescents, most had average (51.6\%) or good (43.9\%) score, only $4 \%$ had poor score.

\section{Mother's Education}

Table 5 shows girls whose mothers were illiterate or educated up to $5^{\text {th }}$ had poor score in $30.17 \%$ and $10.4 \%$, respectively. Good score in $16.3 \%$ and $15.1 \%$, respectively. Girls whose mothers were graduate/postgraduate had good score in $39.8 \%$ and $46.5 \%$ respectively.

\section{Type of Family}

Table 6 shows that girls in nuclear family had better scores $38.3 \%$ had good scores as compared to $30.5 \%$ in joint family group.

\section{Medium}

Table 7 shows that in Hindi-medium majority of girls had average score (63.8\%), 22.3\% had good score, and $13.8 \%$ had poor score. In English-medium girls, majority had average score $(48.4 \%), 41.6 \%$ had good score, and $9.8 \%$ had poor score. Table 8 shows most important source of information was television $29.2 \%$ followed by parents $15.3 \%$, books $11.5 \%$, and newspaper $10.7 \%$. Friends and siblings constituted source of information $48.7 \%$ and $3.4 \%$ respectively. $21.2 \%$ opted for others option.

\begin{tabular}{|c|c|c|}
\hline Age (Years) & Total & Percentage \\
\hline Early Adolescent & 43 & 4.3 \\
\hline Mid Adolescent & 866 & 86.6 \\
\hline
\end{tabular}

\begin{tabular}{|c|c|c|}
\hline Late Adolescent & 91 & 9.1 \\
\hline Grand Total & $\mathbf{1 0 0 0}$ & $\mathbf{1 0 0}$ \\
\hline \multicolumn{3}{|c|}{ Table 1: Age-Wise Distribution of Girls } \\
\hline
\end{tabular}

\begin{tabular}{|c|c|c|}
\hline Type of School & Total & Percentage \\
\hline Hindi-medium government & 340 & 34 \\
\hline English-medium private & 660 & 66 \\
\hline Grand total & 1000 & 100 \\
\hline \multicolumn{2}{|c|}{ Table 2 } \\
\hline
\end{tabular}

\begin{tabular}{|c|c|c|}
\hline Contraception Score & Total & Percentage \\
\hline Poor & 112 & 11.2 \\
\hline Average & 537 & 53.7 \\
\hline Good & 351 & 35.1 \\
\hline Grand Total & $\mathbf{1 0 0 0}$ & $\mathbf{1 0 0}$ \\
\hline \multicolumn{2}{|c|}{ Table 3: Contraception Score }
\end{tabular}

\begin{tabular}{|c|c|c|c|}
\hline \multirow{2}{*}{ Age Group } & \multicolumn{3}{|c|}{ Contraception } \\
\cline { 2 - 4 } & Poor & Average & Good \\
\hline Early & $10(24 \%)$ & $33(76 \%)$ & $0(0 \%)$ \\
\hline Mid & $98(11.3 \%)$ & $457(52.7 \%)$ & $310(36.0 \%)$ \\
\hline Late & $4(4 \%)$ & $47(51.6 \%)$ & $40(43.9 \%)$ \\
\hline Grand Total & $\mathbf{1 1 2}$ & $\mathbf{5 3 7}$ & $\mathbf{3 5 1}$ \\
\hline \multicolumn{4}{|c|}{ Table 4: Age Versus Contraception Score } \\
\hline
\end{tabular}

\begin{tabular}{|c|c|c|c|c|}
\hline \multirow{2}{*}{$\begin{array}{c}\text { Mother's } \\
\text { Education }\end{array}$} & \multicolumn{4}{|c|}{ Contraception Score } \\
\cline { 2 - 5 } Illiterate & $\begin{array}{c}35 \\
(30.1 \%)\end{array}$ & $\begin{array}{c}62 \\
(53.4 \%)\end{array}$ & $\begin{array}{c}19 \\
(16.3 \%)\end{array}$ & 116 \\
\hline Primary & $\begin{array}{c}9 \\
(10.4 \%)\end{array}$ & $\begin{array}{c}64 \\
(74.4 \%)\end{array}$ & $\begin{array}{c}13 \\
(15.1 \%)\end{array}$ & 86 \\
\hline Middle & $\begin{array}{c}13 \\
(13 \%)\end{array}$ & $\begin{array}{c}60 \\
(60 \%)\end{array}$ & $27(27 \%)$ & 100 \\
\hline $\begin{array}{c}\text { Higher } \\
\text { Secondary }\end{array}$ & $5(4 \%)$ & $\begin{array}{c}71 \\
(56.8 \%)\end{array}$ & $\begin{array}{c}49 \\
(39.2 \%)\end{array}$ & 125 \\
\hline Graduate & $\begin{array}{c}25 \\
(6.9 \%)\end{array}$ & $\begin{array}{c}190 \\
(53 \%)\end{array}$ & $\begin{array}{c}143 \\
(39.8 \%)\end{array}$ & 358 \\
\hline Postgraduate & $\begin{array}{c}25 \\
(11.6 \%)\end{array}$ & $\begin{array}{c}90 \\
(41.8 \%)\end{array}$ & $\begin{array}{c}100 \\
(46.5 \%)\end{array}$ & 215 \\
\hline Grand Total & $\mathbf{1 1 2}$ & $\mathbf{5 3 7}$ & $\mathbf{3 5 1}$ & $\mathbf{1 0 0 0}$ \\
\hline \multicolumn{7}{|c|}{ Table 5: Mother's Education to Contraception Score } \\
\hline
\end{tabular}

\begin{tabular}{|c|c|c|c|c|}
\hline \multirow{2}{*}{$\begin{array}{c}\text { Type } \\
\text { of } \\
\text { Family }\end{array}$} & \multicolumn{4}{|c|}{ Contraception Score } \\
\hline & Poor & Average & Good & $\begin{array}{l}\text { Grand } \\
\text { Total }\end{array}$ \\
\hline Nuclear & $\begin{array}{c}63 \\
(10.7 \%)\end{array}$ & $\begin{array}{c}299 \\
(50.9 \%)\end{array}$ & $\begin{array}{c}225 \\
(38.3 \%)\end{array}$ & 587 \\
\hline Joint & $\begin{array}{c}49 \\
(11.8 \%)\end{array}$ & $\begin{array}{c}238 \\
(57.6 \%)\end{array}$ & $\begin{array}{c}126 \\
(30.5 \%)\end{array}$ & 413 \\
\hline $\begin{array}{l}\text { Grand } \\
\text { Total }\end{array}$ & 112 & 537 & 351 & 1000 \\
\hline
\end{tabular}

Table 6: Type of Family to Contraception Score

\begin{tabular}{|c|c|c|c|c|}
\hline \multirow{2}{*}{ Medium } & \multicolumn{4}{|c|}{ Contraception Score } \\
\cline { 2 - 5 } & Poor & Average & Good & $\begin{array}{c}\text { Grand } \\
\text { Total }\end{array}$ \\
\hline Hindi & $\begin{array}{c}47 \\
(13.8 \%)\end{array}$ & $\begin{array}{c}217 \\
(63.8 \%)\end{array}$ & $\begin{array}{c}76 \\
(22.3 \%)\end{array}$ & 340 \\
\hline English & $\begin{array}{c}65 \\
(9.8 \%)\end{array}$ & $\begin{array}{c}320 \\
(48.4 \%)\end{array}$ & $\begin{array}{c}275 \\
(41.6 \%)\end{array}$ & 660 \\
\hline $\begin{array}{c}\text { Grand } \\
\text { Total }\end{array}$ & 112 & 537 & 351 & 1000 \\
\hline \multicolumn{5}{|c|}{ Table 7: Medium-to-Contraception Score } \\
\hline
\end{tabular}




\begin{tabular}{|c|c|c|}
\hline Source of Information & Total & Percentage \\
\hline Mother & 153 & 15.3 \\
\hline Friends & 87 & 8.7 \\
\hline Brother/Sister & 34 & 3.4 \\
\hline Television & 292 & 29.2 \\
\hline Newspaper & 107 & 10.7 \\
\hline Books & 115 & 11.5 \\
\hline Others & 212 & 21.2 \\
\hline Grand Total & 1000 & 100 \\
\hline \multicolumn{3}{|c|}{ Table 8: Source of Information } \\
\hline
\end{tabular}

\section{DISCUSSION}

Knowledge about contraceptives study done in Kuppam Mandal has shown that adolescent girls in rural areas are still ignorant about contraceptives.(8) Similar findings been observed is other Indian studies. $(9,10,11)$

Patnaik D et al (2000) AIIMS, New Delhi, in their study found that all girls were aware that there is a law regarding legal age of marriage, but only (165) 65\% of them knew the correct legal age. Early marriage was preferred by 19 (7.6\%). Although, $214(84.3 \%)$ girls were aware of the small family norm, only 19 (8.8\%) knew the exact norm. Preference for son was reported by 233 (91.3\%).(12) Diane Kittredge in his study found that the adolescents who knew about it most $>90 \%$ knew about the pill. The proportion of girls who knew about condom was low (35\%).(13) Mohammad Reza Mohammad et al (2006) found that almost three quarters (72\%) of participants were aware of condoms, although more than half (53\%) had never seen one. Respondents were more aware of condoms and OCPS (58\%) than other methods like IUD (22\%) and injectables (14\%). 53\% and $41 \%$ were aware of female and male sterilisation respectively. Thirteen percent of adolescents were not aware of any contraceptive methods.(14) Neeru Gupta et al is their study on rural adolescents found that awareness of legal minimum age of marriage was present in more than half of adolescents. Attitude towards marriage beyond 21 yrs. in boys and 18 yrs. in girls was favourable. Mean no. of children desired was $2.2 \pm 1.4$. More boys $(23.7 \%)$ than girls $(9.4 \%)$ wanted three or more children with male preference. Only $19.8 \%$ of adolescents were aware of at least one method of contraception.(15)

\section{Source of Information}

In our study, most important source of information came out to be television (29.2\%) followed by parents $15.3 \%$, books $11.5 \%$, and newspaper $10.7 \%$. Friends and siblings constituted source of information in $8.7 \%$ and $3.4 \%$, respectively. $21.2 \%$ opted for others option.

Chhabra S in his prospective study of school girls showed that knowledge sources were mainly literature and movies (77.9\%).[16]

Singh MM et al in his study found that major sources of information were television $73.1 \%$, radio $37.1 \%$, and parents (36.1\%). Girls preferred to consult parents (49.2\%) and doctors $(44.6 \%)$ for help at times of having reproductive health problems.[17]

Diane Kittredge (2005) in his study found that most adolescents $(70 \%)$ had heard of family planning practices mostly from TV and radio.[13]

\section{CONCLUSION}

It has been demonstrated that positive wellbeing during adolescence predicts better perceived general health and fewer risky health behaviours during young adulthood.(18) Aligned with the goals of the positive youth development perspective, promoting, and nurturing positive wellbeing during the transition from childhood to adolescence may present a promising way to improve long-term health. Reproductive health education as a part of the curriculum can provide an effective means of improving knowledge and reducing reproductive health problems among them.

\section{REFERENCES}

1. World Health Organisation. The reproductive health of adolescence, strategy for action. A joint WHO/UNFA/UNFPA/UNICEF statement. Geneva: WHO 1989:1.

2. Demographic trend for adolescent: ten key facts. Available from: http://www.unilef.org/SOWC 2011/pdfs/Demographictrends.pdf

3. Strategic directions for improving adolescent health in South East Asia. World Health Organisation 2011. Available from: http://www.searo.who.int/linkfiles/publications_SECAH-04.pdf.

4. Bhatia BD, Chandra K. Adolescent mother and an unprepared child. Indian J Mat Child Health 1993;4:6770.

5. Young people health risks and solution: available from:http://www.who.int./mediacentre/factsheets/fs3 45/en/indexhtml.

6. Millennium development goals. Available from: http://www.un.org/millenniumgoals/

7. Implementation guide on RCH-2 ARSH strategy: NRHM, Government of India 2006. Available from: http://www.mohfw.nic.in/NRHM/Documents/ARSH/I mplementation_guide_on_RCH\%2011.pdf.

8. Malleshappa K, Krishna S, Nandini C. Knowledge and attitude about reproductive health among rural adolescents' girls in Kuppam Mandal: an intervention study. Biomedical Research 2011;22(3):305-10.

9. Govt. of India-Ministry of Health and Family Welfare: State wise HIV prevalence (1998-2004) available from www.naco.online.org.

10. Kumar R, Raizada A, Agrawal AK, et al. Adolescent behaviour regarding reproductive health. Indian Journal Paediatrics 2000;67(12):877-82.

11. Bhatia V, Swamy HM. Fertility control methods: knowledge of adolescent girls in schools of Chandigarh. Ind J Med Sci 2000;54(8):342-6.

12. Patnaik D, Lobo J, Kapoor SK, et al. Knowledge and attitudes of rural adolescent girls regarding reproductive health issues. Natl Med J India 2000;13(3):124-8.

13. Kittredge D. Abstinence and abstinence-only education. A Journal of Adolescent Health 2006;39(2):150-1.

14. Mohammad MR, Mohammad K, Farahani FK, et al. Reproductive knowledge, attitudes, and behaviour among adolescent males in Tehran, Iran. International Family Planning Perspectives 2006;32(1):35-44.

15. Gupta N, Mathur AK, Singh MP, et al. Reproductive health awareness of school going, unmarried, rural adolescents. Indian J of Paediatrics 2004;71(9):797-801. 
16. Chhabra S. A step towards helping mothers with unwanted pregnancies. Indian J Matern Child Health 1992;3(2):41-2.

17. Singh MM, Devi R, Gupta SS. Awareness and health seeking behaviour of rural adolescent school girls on menstrual and reproductive health problems in Haryana. Indian Journal of Medical Sciences 1999;53(10):439-43.
18. Hoyt LT, Chase-Lansdale PL, McDade TW, et al. Positive youth, healthy adults: does positive wellbeing in adolescence predict better perceived health and fewer risky health behaviours in young adulthood? J Adolesc Health 2012;50(1):66-73. 